\title{
PENGARUH POLA PENGELUARAN ZAKAT INFAQ DAN SHADAQAH TERHADAP LOYALITAS SERTA PENINGKATAN KESEJAHTERAAN MUZAKKI DAN MUSTAHIQ DI SULAWESI SELATAN
}

\author{
Muhammad Yusuf $\mathbf{Q}^{1}$ \\ Hapid $^{2}$
}

No. HP $08124211468^{1}, 081242455731^{2}$

\begin{abstract}
ABSTRAK
Penelitian ini bertujuan untuk menjadi masukan kepada pemerintah dalam bentuk kebijakan institusi Badan Amil Zakat (BAZ) terkait pola pengeluaran Zakat Infaq dan Shadaqah (ZIS) sehingga dapat memberi manfaat yang berarti terhadap sistem dan kebijakan terhadap pengelolaan ZIS bagi pemerintah dan masyarakat.

Metode yang akan digunakan dalam pencapaian tujuan tersebut adalah metode penelitian kuantitatif yang titik beratnya diletakkan pada kenyataan sebenarnya, yakni mempelajari hubungan variabel-variabel yang menggunakan alat analisis statistik Partial Least Square (PLS). Permasalahan yang bersifat normatif dilakukan analisis kualitatif dengan metode intuitif (kasyf) untuk menelaah hakekat yang terkandung dalam pelaksanaan perintah ZIS, tingkat loyalitas muzakki serta kesejahteraan, baik muzakki maupun mustahiq.

Hasil penelitian menunjukkan bahwa Pola pengeluaran ZIS berpengaruh signifikan terhadap Loyalitas Muzakki (H1). Nilai t-statistics sebesar 20,8751, yang menunjukkan angka yang lebih besar dari $t$-tabel $=1,96$. $t_{\text {-statistik }}(20,8751)>t_{\text {tabel }}$ $(1,96)$. Pola pengeluaran ZIS berpengaruh signifikan terhadap keejahteraan muzakki (H2). Nilai t-statistics sebesar 3,8185, yang menunjukkan angka yang lebih besar dari t-tabel $=1,96$. $t_{\text {-statistik }}(3,8185)>t_{\text {-tabel }}(1,96)$. Loyalitas tidak ada pengaruh yang signifikan terhadap kesejahteraan muzakki (H3). Nilai t-statistics sebesar 0,1533, yang menunjukkan angka yang lebih kecil dari $t$-tabel $=1,96$. $t_{\text {-statistik }}(0,1533) \leq t$ tabel $(1,96)$. Loyalitas berpengaruh signifikan terhadap kesejahteraan mustahiq (H4). Nilai $t$ statistics sebesar 2,5930, yang menunjukkan angka yang lebih besar dari $t$-tabel $=1,96$. $t_{\text {-statistik }}$ $(2,5930)>t_{\text {-tabel }}(1,96)$, dan Kesejahteraan muzakki tidak ada pengaruh yang signifikan terhadap kesejahteraan mustahiq (H5). Nilai tstatistics sebesar 1,1583, yang menunjukkan
\end{abstract}

angka yang lebih kecil dari $t$-tabel $=1,96$. $t$ statistik $(1,1583) \leq t_{\text {tabel }}(1,96)$.

Kesimpulan dari penelitian ini bahwa secara parsial varibel $X$ pada $H 1, H 2$, dan $H 4$ berpengruh secara signifikan terhadap variabel $Y$, sedangkan variabel $X$ pada $\mathrm{H} 3$ dan H5 tidak ada pengruh yang signifikan terhadap variabel $Y$. dan secara simultan memberi pengaruh yang signifikan.

Kata Kunci: Zakat, Infaq, Shadaqah, Loyalitas, Kesejahteraan, Muzakki, Mustahiq

\section{PENDAHULUAN}

Prinsip-prinsip dasar Islam tentang pembangunan dengan segala aspeknya, terutama masalah pembangunan ekonomi adalah suatu hal yang menarik untuk dikaji lebih mendalam, sebab disatu pihak diharapkan dapat memecahkan masalahmasalah ekonomi yang melanda dunia sepanjang masa dengan ajaran-ajarannya yang lengkap, sementara dilain pihak merupakan cabang dari ilmu pengetahuan yang dijiwai oleh ajaran agama Islam yang belum sepenuhnya dapat diterima oleh dunia secara keseluruhan.

Konsepsi Islam tentang perekonomian yang biasa juga disebut "Sistem Ekonomi Islam/Syariah" lebih banyak menekankan aturan-aturan perekonomian secara individu, 
sehingga unsur moral lebih dititik beratkan. Aturan-aturan pokok tentang perekonomian dalam Islam pada dasarnya sudah lengkap dan utuh, maka dalam upaya membangun perekonomian, selain formulasi-formulasi pemikiran baru yang berpangkal dari alQur'an dan Sunnah, juga dituntut adanya pembenahan moral bagi setiap individu pendukungnya.

Konsep ekonomi konvensional dewasa ini telah terbukti semakin mengukuhkan terakumulasinya faktor-faktor produksi pada sekelompok masyarakat (konglemerasi), sehingga semakin memperlebar gap antara orang-orang kaya dengan orang-orang miskin. Karena itu dibutuhkan pemikiran secara mendalam (kontemplatif) untuk memformulasi sistem ekonomi kedepan agar dapat membawa ummat manusia kepada kesejahteraan lahir dan bathin.

Konsep zakat, infaq dan shadaqah (ZIS) dalam ekonomi Islam, adalah institusi yang menarik untuk dikaji lebih lanjut dalam kaitannya dengan pola pengeluaran dan tingkat kesejahteraan mustahiq, serta penguatan dari sisi institusi pengumpul zakat, infaq dan shadaqah. Lebih jauh diharapkan akan memberikan gambaran secara jelas dan menyakinkan bahwa dengan ketaatan muzakki dalam membayar zakat, infaq dan shadaqah akan berdampak semakin membaiknya kualitas hidup dalam arti sejahtera lahir dan bathin, baik terhadap muzakki itu sendiri maupun terhadap mustahiq.
Zakat, infaq dan shadaqah (ZIS) sesungguhnya dapat dijadikan sebagai sarana pengentasan kemiskinan karena dapat memperkecil kesenjangan pendapatan antar golongan dalam masyarakat, sekaligus dapat menjadi pintu bagi terciptanya motivasi pada sektor rill, jika pengelolaan ZIS diarahkan pada bentuk yang lebih produktif.

Dewasa ini kondisi yang ada pada BAZ baik pada tingkat nasional, provinsi atau kabupaten/kota belum dikelola secara profesional dan belum menunjukkan keterbukaan manajemen pengelolaan ZIS yang baik. Hal ini terjadi karena memang secara internal masih terdapat permasalahan manajemen dan operasional pada lembagalembaga pengelola ZIS. Disisi lain dapat juga kerena lembaga-lembaga pengelola ZIS tersebut tidak (belum) membuka akses informasi yang luas bagi masyarakat untuk memperkenalkan dan menarik sebanyak mungkin sumber-sumber ZIS dari masyarakat (muzakki). Karena itu dapat dipahami bahwa loyalitas muzakki pada BAZ belum optimal.

\section{METODE PENELITIAN}

Penelitian ini akan dilaksanakan pada empat wilayah Kota/ Kabuapten yang berada di Sulawesi Selatan yaitu Kabupaten Luwu, Kota Palopo, Kabupaten Luwu Utara dan Kabupaten Luwu Timur dengan pertimbangan bahwa daerah tersebut memiliki latar belakang (kultur budaya) yang sama dan memiliki kesamaan visi dan misi terhadap upaya menjadikan Al-Qur'an sebagai 
pedoman utama dalam pelaksanaan pemerintahan dan kehidupan masyarakat.

Keempat Kota/Kabupaten tersebut diatas adalah hasil pemekaran dari Kabupaten Luwu (yang dikenal dengan "bumi sawerigading"), sehingga kultur budaya dalam masyarakat dari keempat Kota/Kabupaten tersebut sama dan sampai sekarang masih dipersatukan dengan simbol "Datu Luwu" yang sekaligus mengikat secara adat, budaya, bahasa dan agama.

Dalam penelitian ini populasi meliputi muzakki dan mustahiq yang berada di empat Kabupaten/Kotadi Sulawesi Selatan, yaitu Kabupaten Luwu, Kota Palopo, Kabupaten Luwu Utara dan Kabupaten Luwu Timur. Sedangkan sampel adalah sejumlah individu yang merupakan perwakilan dari populasi yang akan diteliti dengan menggunakan metode pengambilan sampel proporsional random sampling, yang dipilih secara proporsional pada setiap daerah Kabupaten/Kota dengan menggunakan rumus Slovin (Sevilla, 1993). Adapun metode pengumpulan data yang digunakan yaitu Kuesioner, Wawancara, dan Dokumentasi. Sedangkan klasifikasi variabel sebagaimana telah diuraikan sebelumnya bahwa variabel penelitian terdiri dari 4 variabel yang meliputi variabel Pola Pengeluaran ZIS (X1) sebagai variabel eksogen dan varibel endogen terdiri dari Loyalitas (Y1), Kesejahteraan Muzakki (Y2) dan Kesejahteraan Mustahiq (Y3).

\section{HASIL DAN PEMBAHASAN}

Penelitian ini menggunakan empat variabel utama yaitu Pola Pengeluaran ZIS (X1) sebagai variabel eksogen dan varibel endogen terdiri dari Loyalitas (Y1), Kesejahteraan Muzakki (Y2) dan Kesejahteraan Mustahiq (Y3). Pada pembahasan berikutnya, akan disajikan analisis hasil studi terhadap keempat variabel utama tersebut.

\section{Analisis Model}

Analisis model dengan menggunakan metode Partial Least Square (PLS) yang meliputi (1) analisis model pengukuran (measurement model), dan (2) analisis model struktural (struktural model). Analisis model pengukuran berdasarkan outer model atau measurement model adalah penilaian terhadap validitas dan reliabilitas variabel penelitian. Analisis ini mengukur hubungan antara konstrak dengan indikatornya, artinya seberapa besar konstrak mampu mengandung keragaman data yang ada dalam setiap indikator dan seberapa besar keterkaitan hubungan antara konstrak dengan indikator-indikatornya. Dalam hal ini ada tiga kriteria untuk menilai outer model, yaitu convergent validity, discriminant validity, dan composite reliability. Model struktural berdasarkan inner model atau structural model,bertujuan untuk menguji hipotesis penelitian yang telah ditentukan sebelumnya, karena itu pengujian model struktural dilakukan untuk melihat hubungan antara konstrak. 
Analisis Model Pengukuran (Measurement Model)

Analisis model pengukuran (measurement model) yang digunakan melalui analisis faktor konfirmatori dengan menggunakan pendekatan MTMM (MultiTrait-Multi Method)dengan menguji validitas convergent dan discriminant. (Campbell dan Fiske, 1959, dalam Latan, 2012 : 78). Validitas convergent berhubungan dengan prinsip bahwa indikator-indikator dari suatu konstrak seharusnya berkorelasi tinggi. Validitas discriminant berhubungan dengan prinsip bahwa indikator-indikator konstrak yang berbeda seharusnya tidak berkorelasi tinggi.

\section{Uji Convergent Validity}

Uji convergent validity indikator reflektif dapat dilihat dari nilai loading factor untuk tiap indikator konstrak. Angka yang digunakan untuk menilai convergent validity yaitu nilai loading factor harus lebih besar dari 0,7 untuk penelitian yang bersifat confirmatory dan nilai loading factoranatara 0,6 - 0,7 untuk penelitian yang bersifat exploratory masih dapat diterima serta nilai average variance extracted (AVE) harus lebih besar dari 0,5. Oleh karena penelitian ini masih dalam tahap pengembangan skala pengukuran, maka kriteria validitas convergent (convergent validity) menggunakan batas minimal nilai loading factor 0,5 - 0,6 masih dianggap cukup
(Chin, 1998 dalam Latan, 2012 : 78). Atau harga $t$ statistik $>t_{\text {tabel. }}$. Harga $t t_{\text {tabel }}$ dengan derajat bebas $>120$ dengan harga $\alpha=0,05$ adalah 1,96 . Output nilai loading factor ini dapat dilihat dalam Tabel 1 berikut. 
Tabel 1

\section{HASIL UJI CONVERGENT VALIDITY OUTER LOADING(REFLEKTIF)}

\begin{tabular}{|c|c|c|c|c|c|}
\hline Konstruk & $\begin{array}{c}\text { Original } \\
\text { Sample } \\
(\mathrm{O})\end{array}$ & $\begin{array}{c}\text { Sample } \\
\text { Mean (M) }\end{array}$ & $\begin{array}{l}\text { Standard } \\
\text { Deviation } \\
\text { (STDEV) }\end{array}$ & $\begin{array}{c}\text { Standard } \\
\text { Error } \\
\text { (STERR) }\end{array}$ & $\begin{array}{l}\text { T-Statistics } \\
\text { (O/STERR) }\end{array}$ \\
\hline X1.1 $\leftarrow$ Pola Pengluaran ZIS (X1) & 0.8087 & 0.8013 & 0.0508 & 0.0508 & 15.9331 \\
\hline X1.2 $\leftarrow$ Pola Pengeluaran ZIS (X1) & 0.7218 & 0.155 & 0.0452 & 0.0452 & 15.9688 \\
\hline $\mathrm{X} 1.3 \leftarrow$ Pola Pengeluaran ZIS (X1) & 0.7094 & 0.4170 & 0.1228 & 0.1228 & 3.3340 \\
\hline $\mathrm{Y} 1.1 \leftarrow$ Loyalitas $(\mathrm{Y} 1)$ & 0.7838 & 0.5745 & 0.0834 & 0.0834 & 6.9955 \\
\hline $\mathrm{Y} 1.2 \leftarrow$ Loyalitas $(\mathrm{Y} 1)$ & 0.7706 & 0.7604 & 0.0436 & 0.0436 & 17.6797 \\
\hline $\mathrm{Y} 1.3 \leftarrow$ Loyalitas $(\mathrm{Y} 1)$ & 0.7105 & 0.4880 & 0.0525 & 0.0525 & 9.3472 \\
\hline Y2.1 $\leftarrow$ Kesejahteraan Muzakki (Y2) & 0.9652 & 0.9566 & 0.0296 & 0.0296 & 32.6567 \\
\hline Y2.2 $\leftarrow$ Kesejahteraan Muzakki (Y2) & 0.7996 & 0.6021 & 0.0987 & 0.0987 & 6.0778 \\
\hline Y2.3 $\leftarrow$ Kesejahteraan Muzakki (Y2) & 0,8649 & 0,5968 & 0,0945 & 0,0749 & 8,2735 \\
\hline Y2.4 $\leftarrow$ Kesejahteraan Muzakki (Y2) & 0,8234 & 0,7095 & 0,0594 & 0,0395 & 4,8654 \\
\hline Y2.5 $\leftarrow$ Kesejahteraan Muzakki (Y2) & 0,9345 & 0,4387 & 0,4867 & 0,0924 & 9,3575 \\
\hline $\begin{array}{c}\text { Y3.1 } \rightarrow \text { Kesejahteraan Mustahiq } \\
(\text { Y3) }\end{array}$ & 0.8165 & 0.2780 & 0.2148 & 0.2148 & 2.1435 \\
\hline $\begin{array}{l}\text { Y3.2 } \rightarrow \text { Kesejahteraan Mustahiq } \\
\text { (Y3) }\end{array}$ & 0.7328 & 0.5277 & 0.2353 & 0.2353 & 2.5858 \\
\hline $\begin{array}{l}\text { Y3.3 } \rightarrow \text { Kesejahteraan Mustahiq } \\
\text { (Y3) }\end{array}$ & 0.9912 & 0.4555 & 0.2134 & 0.2134 & 2.3137 \\
\hline $\begin{array}{c}\text { Y3.4 } \rightarrow \text { Kesejahteraan Mustahiq } \\
\text { (Y3) }\end{array}$ & 0.8396 & 0.1912 & 0.1703 & 0.1703 & 1.9724 \\
\hline
\end{tabular}

Sumber : Data primer diolah, 2013

Tabel 1 di atas dapat memperlihatkan bahwa nilai-nilai yang ada pada kolom original sample untuk X1.1, X1.2, X1.3 sampai Y3.1, Y3.2, Y3.3, Y3.4 semuanya memiliki nilai diatas 0,7 . sehingga dapat dikatakan bahwa semua indikator valid dalam mengukur konstraknya.

\section{Uji Discriminant Validity}

Pemeriksaan selanjutnya adalah pemeriks model pengukuran yang dinilai berdasarkan cross loading dan membandingkan antar konstrak. Discriminant validity yang baik akan mampu menjelaskan varian indikatornya lebih tinggi dibandingkan dengan varian dari indikator konstrak lainnya. Cross loading menggambarkan korelasi antara suatu indikator dengan konstraknya dan dengan 
konstrak lainnya. Jika korelasi konstrak dengan item pengukuran (setiap indikatornya) lebih tinggi dari korelasi dengan indikator dari konstrak lainnya, maka hal ini menunjukkan konstrak laten tersebut mampu memprediksi indikatornya dengan lebih baik dari pada konstrak lainnya (Yamin, 2009 : 42). Hasil dari cross loading dapat dilihat pada Tabel 2.

Tabel 2

CROSS LOADING UNTUK UJI DISCRIMINANT VALIDITY

\begin{tabular}{|lc|c|c|c|c|}
\hline \multicolumn{1}{|c|}{ Indikator } & & $\begin{array}{c}\text { Pola } \\
\text { Pengeluaran } \\
\text { ZlS }\end{array}$ & Loyalitas & $\begin{array}{c}\text { Kesejahteraan } \\
\text { Muzakki }\end{array}$ & $\begin{array}{c}\text { Kesejahteraan } \\
\text { Mustahiq }\end{array}$ \\
\hline Zakat & $\mathrm{X} 1.1$ & 0.8087 & 0.5953 & 0,3586 & 0,4437 \\
\hline Infaq & $\mathrm{X} 1.2$ & 0.7218 & 0.4367 & 0,1315 & 0,1304 \\
\hline Shadaqah & $\mathrm{X} 1.3$ & 0.4094 & 0.3151 & 0,0583 & 0,0809 \\
\hline Kurang Loyal & $\mathrm{Y} 1.1$ & 0.3498 & 0.5838 & 0,1068 & 0,0956 \\
\hline Loyal & Y1.2 & 0.5498 & 0.7706 & 0,1474 & 0,4664 \\
\hline Sangat Loyal & Y1.3 & 0.3331 & 0.4905 & 0,1830 & 0,1238 \\
\hline Hifzud-din & Y2.1 & 0.3337 & 0.2397 & 0,9652 & 0,1908 \\
\hline Hifzun-nafs & Y2.2 & 0.1211 & 0.0885 & 0,5996 & 0,0261 \\
\hline Hifzul-aql & Y.2.3 & 0,1547 & 0,3334 & 0,8763 & 0,0967 \\
\hline Hifzul-mal & Y2.4 & 0,3335 & 0,2975 & 0,5667 & 0,2943 \\
\hline Hifzun-nasl & Y2.5 & 0,2467 & 0,2719 & 0,7692 & 0,3328 \\
\hline Fakir & Y3.1 & 0.2369 & 0.2241 & 0,0003 & 0,5165 \\
\hline Miskin & Y3.2 & 0.2486 & 0.2580 & 0,1216 & 0,7328 \\
\hline Subsistan & Y.3.3 & 0.1928 & 0.1974 & 0,1200 & 0,5912 \\
\hline Muzakki & Y.3.4 & 0.1125 & 0.0944 & 0,0193 & 0,2396 \\
\hline
\end{tabular}

Sumber : Data primer diolah, 2013

Sebagai contoh, Tabel 2 di atas memperlihatkan bahwa nilai loading factor untuk indikator X1.1 adalah 0,8087 . Indikator ini memiliki korelasi yang lebih tinggi dengan konstrak lainnya, yaitu Loyalitas $(0,5953)$, Kesejahteraan Muzakki (0,3586), dan Kesejahteraan Mustahiq $(0,4437)$. Semua nilai loading factor dalam konstrak Pola
Pengeluaran ZIS memiliki korelasi yang lebih tinggi dibanding dengan konstrak lainnya. Hal ini menunjukkan konstrak Pola Pengeluaran ZIS mampu menjelaskan varian yang lebih tinggi dengan indikator X1.1 - X1.3 dibanding dengan indikator lainnya. Indikator Y1.1 - Y1.3 memiliki korelasi yang lebih tinggi dengan konstrak Loyalitas dibanding dengan 
nilai korelasi dengan konstrak lainnya. Indikator Y2.1 - Y2.5 memiliki korelasi yang lebih tinggi dengan konstrak Kesejahteraan Muzakki dibanding dengan nilai korelasi dengan konstrak lainnya. Begitu juga dengan Y3.1 - Y3.4 memiliki korelasi yang lebih tinggi dengan konstrak Kesejahteraan Mustahiq dibanding dengan nilai korelasi dengan konstrak lainnya.

\section{Uji Reliabilitas (Reliability)}

Evaluasi ketigaadalah melihat composite reliability atau reliabilitas konstrak yang digambarkan oleh tabel composite reliability.
Statistik yang digunakan adalah cronbach'salpha atau composite reliability. Pemeriksaan convergent validity dikatakan reliable jika nilai cronbach'salpha atau composite reliabilitydi atas 0,7 dengan kata lain menunjukkan konstrak memiliki reliabilitas atau keandalan yang tinggi sebagai alat ukur (Yamin, 2009 : 41). Namun demikian nilai cronbach's alpha yang dihasilkan oleh PLS sedikit under estimate sehingga lebih disarankan untuk menggunakan composite reliability (Latan, 2012 : 100). Hasil pengujian tersebut dapat dilihat pada Tabel 3 berikut :

\section{Tabel 3}

\section{OVERVIEW CONSTRUCT INTERNAL CONSISTENCY}

\begin{tabular}{|l|c|c|c|c|c|c|}
\hline & AVE & $\begin{array}{c}\text { Composite } \\
\text { Reliability }\end{array}$ & $\begin{array}{c}\text { R } \\
\text { Square }\end{array}$ & $\begin{array}{c}\text { Cronbachs } \\
\text { Alpha }\end{array}$ & $\begin{array}{c}\text { Commu- } \\
\text { nality }\end{array}$ & $\begin{array}{c}\text { Redu- } \\
\text { dancy }\end{array}$ \\
\hline Kesejahteraan Mustahiq (Y3) & & & 0.1307 & & 0.2489 & 0.0048 \\
\hline Kesejahteraan Muzakki (Y2) & 0.6455 & 0.7755 & 0.1034 & 0.5395 & 0.6455 & 0.0037 \\
\hline Loyalitas (Y1) & 0.5819 & 0.7501 & 0.4873 & 0.5972 & 0.3819 & 0.1822 \\
\hline Pola Pengeluaran ZIS (X1) & 0.5476 & 0.7428 & & 0.3904 & 0.4476 & \\
\hline
\end{tabular}

Sumber : Output Smart PLS, 2013

Berdasarkan hasil Tabel 3 di atas, dapat diketahui bahwa nilai-nilai composite reliabiliy diatas 0,7 , sehingga dapat dikatakan konstrak memiliki reliabilitas yang baik sebagai alat ukur. Dapat dilihat pula bahwa nilai-nilai composite reliability lebih tinggi untuk semua konstak dibandingkan dengan nilai cronbach's alpha.

\section{Analisis Model Struktural (Structural Model)}

Evaluasi model struktural bertujuan untuk melihat signifikansi setiap koefisien jalur yang menyatakan apakah ada signifikansi atau tidak adanya pengaruh antar variabel laten. Pengujian koefisien jalur pada inner model berarti juga meguji hipotesis yang telah ditetapkan yang tercermin pada jalur-jalur yang ada pada model. 
Untuk menyimpulkan apakah hipotesis diterima atau ditolak digunakan kriteria : Jika $\mathrm{t}_{\text {-statistik }}>$ dari $\mathrm{t}_{\text {-tabel }}$ pada derajat bebas dan tingkat kesalahan $(\alpha)$ yang ditetapkan. Dalam penelitian ini harga $t_{-}$tabel dengan derajat bebas $>120$ dengan harga $\alpha=0,05$ adalah 1,96 .
Jika $\mathrm{t}_{\text {-statistik }} \geq \mathrm{t}_{\text {tabel }}(1,96) \quad$;artinya terdapat pengaruh positif (signifikan), maka $\mathrm{Ha}$ diterima dan Ho ditolak. Jika $\mathrm{t}_{\text {-statistik }} \leq \mathrm{t}_{\text {tabel }}$ $(1,96)$; artinya tidak terdapat pengaruh positif (tidak signifikan), maka $\mathrm{Ha}$ ditolak dan Ho diterima.Hasil pengujian hipotesis jalur dapat dilihat pada Tabel 4 berikut :

\section{Tabel 4}

HASIL PENGUJIAN HIPOTESIS (PATH MODELING)

\begin{tabular}{|c|c|c|c|c|c|c|c|c|}
\hline Hip & Jalur & & $\begin{array}{c}\text { Original } \\
\text { Sample } \\
\text { Estimate } \\
\text { (O) }\end{array}$ & $\begin{array}{l}\text { Sample } \\
\text { Mean } \\
\text { (M) }\end{array}$ & $\begin{array}{l}\text { Standard } \\
\text { Deviation } \\
\text { (STDEV) }\end{array}$ & $\begin{array}{l}\text { Standard } \\
\text { Error } \\
\text { (STERR) }\end{array}$ & $\begin{array}{c}\text { T- } \\
\text { Statistik }\end{array}$ & Ket. \\
\hline $\mathrm{H} 1$ & $\begin{array}{l}\text { Pola Pengeluaran } \\
\text { ZIS } \\
\text { Loyalitas }\end{array}$ & $\rightarrow$ & 0.6981 & 0.6988 & 0.0334 & 0.0334 & 20.8751 & $\begin{array}{l}\text { Signi- } \\
\text { fikan }\end{array}$ \\
\hline $\mathrm{H} 2$ & $\begin{array}{l}\text { Pola Pengeluaran } \\
\text { ZIS } \\
\text { Kesejahteraan } \\
\text { Muzakki }\end{array}$ & $\rightarrow$ & 0.3120 & 0.3073 & 0.0817 & 0.0817 & 3.8185 & $\begin{array}{l}\text { Signi- } \\
\text { fikan }\end{array}$ \\
\hline $\mathrm{H} 3$ & $\begin{array}{l}\text { Loyalitas } \\
\text { Kesejahteraan } \\
\text { Muzakki }\end{array}$ & $\rightarrow$ & 0.0135 & 0.0226 & 0.0884 & 0.0884 & 0.1533 & $\begin{array}{l}\text { Tdk } \\
\text { Signi- } \\
\text { fikan }\end{array}$ \\
\hline $\mathrm{H} 4$ & $\begin{array}{l}\text { Loyalitas } \\
\text { Kesejahteraan } \\
\text { Mustahiq }\end{array}$ & $\rightarrow$ & 0.3271 & 0.3255 & 0.1261 & 0.1261 & 2.5930 & $\begin{array}{l}\text { Signi- } \\
\text { fikan }\end{array}$ \\
\hline $\mathrm{H} 5$ & $\begin{array}{l}\text { Kesejahteraan } \\
\text { Muzakki } \\
\text { Kesejahteraan } \\
\text { Mustahiq }\end{array}$ & $\rightarrow$ & 0.0960 & 0.0984 & 0.0828 & 0.0828 & 1.1583 & $\begin{array}{l}\text { Tdk } \\
\text { Signi- } \\
\text { fikan }\end{array}$ \\
\hline
\end{tabular}

Sumber : Data diolah, 2013

${ }^{*}$ ) signifikan $5 \%$; two side test $t_{\text {tabel }}=1,96$, dengan derajat bebas $>120$

$\mathrm{t}_{\text {-statistik }}(20,8751)>\mathrm{t}_{\text {-tabel }}(1,96)$.Artinya Ho

\section{KESIMPULAN}

Berdasarkan hasil perhitungan inner model pada Tabel 4 di atas dapat disimpulkan sebagai berikut:

1. Hipotesis Pertama

Dari hasil uji nilai $t$-statistics sebesar 20,8751, yang menunjukkan angka yang lebih besar dari t-tabel =1,96. ditolak dan $\mathrm{Ha}$ diterima. Jadi dapat disimpulkan bahwa terdapat pengaruh yang signifikan dari variabel Pola pengeluaran ZIS terhadap loyalitas, artinya bahwa semakin besar / baik pola pengeluaran ZIS, maka akan semakin besar / baik pula loyalitas. Dengan kata lain jika kualitas pola pengeluaran ZIS ditingkatkan secara baik, maka akan 
dapat memberikan dampak yang signifikan terhadap loyalitas. Dengan demikian maka hipotesis pertama terbukti dan dapat diterima.

2. Hipotesis Kedua

Dari hasil uji nilai $t$-statistics sebesar 3,8185, yang menunjukkan angka yang lebih besar dari t-tabel $=1,96 . \quad \mathrm{t}_{\text {-statistik }}(3,8185)>\mathrm{t}$-tabel $(1,96)$. Artinya $\mathrm{Ho}$ ditolak dan $\mathrm{Ha}$ diterima. Jadi dapat disimpulkan bahwa terdapat pengaruh yang signifikan dari variabel pola pengeluaran ZIS terhadap kesejahteraan muzakki, artinya bahwa semakin besar / baik pola pengeluaran ZIS, maka akan semakin besar / baik pula kesejahteraan muzakki. Dengan kata lain jika kualitas pola pengeluaran ZIS ditingkatkan secara baik, maka akan dapat memberikan dampak yang signifikan terhadap kesejahteraan muzakki. Dengan demikian maka hipotesis kedua terbukti dan dapat diterima.

3. Hipotesis Ketiga

Dair hasil uji nilai $t$-statistics sebesar 0,1533, yang menunjukkan angka yang lebih kecil dari t-tabel $=1,96 . \mathrm{t}_{\text {-statistik }}(0,1533) \leq \mathrm{t}_{\text {-tabel }}(1,96)$. Artinya Ho diterima dan $\mathrm{Ha}$ ditolak. Jadi dapat disimpulkan bahwa tidak ada pengaruh yang signifikan dari variabel loyalitas terhadap kesejahteraan muzakki, artinya bahwa semakin besar / baik loyalitas, tidak akan memberi dampak secara signifikan terhadap kesejahteraan muzakki. Dengan kata lain jika kualitas loyalitas ditingkatkan secara baik, maka tidak akan dapat memberikan dampak yang signifikan terhadap kesejahteraan muzakki. Dengan demikian maka hipotesis ketiga tidak terbukti dan tidak dapat diterima (ditolak).

4. Hipotesis Keempat

Dari hasil uji nilai $t$-statistics sebesar 2,5930, yang menunjukkan angka yang lebih besar dari t-tabel $=1,96 . \quad \mathrm{t}^{-}$-statistik $(2,5930)>\mathrm{t}^{-}$tabel $(1,96)$.Atinya $\mathrm{Ho}$ ditolak dan $\mathrm{Ha}$ diterima. Jadi dapat disimpulkan bahwa terdapat pengaruh yang signifikan dari variabel loyalitas terhadap kesejahteraan mustahiq, artinya bahwa semakin besar / baik loyalitas, maka akan semakin besar / baik pula kesejahteraan mustahiq. Dengan kata lain jika kualitas loyalitas ditingkatkan secara baik, maka akan dapat memberikan dampak yang signifikan terhadap kesejahteraan mustahiq. Dengan demikian maka hipotesis keempat terbukti dan dapat diterima.

5. Hipotesis Kelima

Dari hasil uji nilai $t$-statistics sebesar 1,1583, yang menunjukkan angka yang lebih kecil dari t-tabel 
$=1,96 . \mathrm{t}$-statistik $(1,1583) \leq \mathrm{t}^{- \text {tabel }}(1,96)$. Artinya $\mathrm{Ho}$ diterima dan $\mathrm{Ha}$ ditolok. Jadi dapat disimpulkan bahwa tidak ada pengaruh yang signifikan dari variabel kesejahteraan muzakki terhadap kesejahteraan mustahiq, artinya bahwa semakin besar / baik kesejahteraan muzakki, tidak akan memberi dampak secara signifikan terhadap kesejahteraan mustahiq. Dengan kata lain jika kualitas kesejahteraan muzakki ditingkatkan secara baik, maka tidak akan dapat memberikan dampak yang signifikan terhadap kesejahteraan mustahiq. Dengan demikian maka hipotesis kelima tidak terbukti dan tidak dapat diterima (ditolak).

\section{SARAN-SARAN}

Berdasarkan pada hasil, pembahasan dan simpulan dari penelitian ini, maka berikut ini dirumuskan beberapa saran sebagai berikut :

1. Bagi Muzakki, disarankan untuk berusaha belajar dan memahami kandungan alQur'an dan as-Sunnah, khususnya terhadap hal-hal yang terkait dengan perintah zakat. Dengan pemahaman yang baik, muzakki diharapkan dapat mengimplementasikan dan membudayakan kebiasaan berzakat dan kewajiban-kewajiban lainnya dengan baik dan benar sesuai dengan tuntunan alQur'an dan as-Sunnah.
2. Bagi Lembaga Zakat, disarankan untuk berupaya meningkantkan sistem pengelolaan zakat dengan manajemen yang lebih transparan dan meningkatkan sumberdaya manusia yang ada, dengan demikian kepercayaan masyarakat (muzakki) terhadap lembaga zakat akan lebih baik dan akan mendorong untuk lebih menyalurkan zakatnya pada lembaga yang ada. Disamping itu hendaknya ada upaya-upaya yang konkrit dilakukan untuk memberi pemahaman kepada muzakki tentang kewajiban zakat dan manfaatnya bagi kesejahteraan ummat, seperti kegiatan sosialisasi zakat gerakan berzakat yang dimulai dari para pemangku kepentingan, seperti para pejabat, ulama dan tokoh masyarakat.

3. Bagi Pemerintah, disarankan untuk lebih mendorong dan mengoptimalkan peran dan fungsi lembaga zakat yang ada dengan membuat regulasi yang dapat memberi pedoman yang lebih nyata dan lebih aplikatif terhadap lembaga zakat dalam menjalankan fungsi dan perannya sebagai pengelola dana ummat.

4. Bagi Peneliti Lanjutan, diharapkan dapat mengembangkan dan memperluas kajian dari nilai-nilai Islam dengan mengembangkan indikator-indikator dan vaiabel-variabel yang sesuai syariah yang belum diteliti, sehingga lingkup pembahasan akan semakin luas terhadap pengembangan ilmu ekonomi Islam. 


\section{DAFTAR PUSTAKAN}

\section{Jurnal / Artikel / Makalah :}

Beik, Irfan Syauqi, 2008, Artikel Berjudul : Zakat Perusahaan dan Kemaslahatan Umat, Republika Online http://www.republik a.co.id, diunduh tanggal 14 April 2008

Mengentaskan

2008, Artikel Berjudul : Zakat untuk Kemiskinan, http://us.mc371.mail.yahoo.com/mc/compose ?to=gibeiktop@yahoo.com , diunduh tanggal 21 Juli 2008

Zadjuli, Suroso Imam, Prof. Dr. H., 2006, Kesejahteraan dan Keadilan dalam Perspektif Islam. Makalah disampaikan dalam seminar "Islam dan Isu-Isu Kontemporer" di Kantor Pusat IAIN Sunan Ampel Surabaya yang diselenggarakan oleh Fakultas UshuluddinIAIN Sunan Ampel Surabaya bekerjasama dengan Universitas Kebangsaan Malaysia pada tanggal 6 Juni 2006.

\section{Buku - Buku :}

Ali, Mohammad Daud, 1988, Sistem Ekonomi Islam Zakat dan Wakaf, Penerbit Universitas Indonesia (UI-Press), Jakarta.

Afzalurrahman, 1996, Doktrin Ekonomi Islam, PT. Dana Bhakti Wakaf, Jogyakarta.

Utsaimin, Syaikh Muhammad Shalih, 2008, Ensiklopedi Zakat, Pustaka AsSunnah, Jakarta.

Apraiyyah, M. Hamdar, 2007, Meneropong Fenomena Kemiskinan, Telaah Perspektif Al-Qur'an, Pustaka Pelajar, Yogyakarta.

Chapra, M. Umer, 2001, The Future of Economics : An Islamic Perspective, Shari'ah Economics and Banking Institute (SEBI), Jakarta.

Gamal, Merza, 2006, Model Dinamika Sosial Ekonomi Islam, Solusi Pembangunan Kesejahteraan Berkesinambungan dan Berkeadilan, Penerbit Unri Press, Pekanbaru.

Ghani, Abdul, 2005, The Spiritually In Business Pencerahan Hati Bagi Pelaku Usaha, Pena Pundi Aksara, Jakarta

Hafidhuddin, Didin, 2004, Zakat Infak Sedekah, Cetakan Keempat, Gema Insani, Jakarta

Mannan, M. Abdul, Prof., Ph.D., 1997, Teori dan Praktek Ekonomi Islam, PT. Dana Bhakti Wakaf, Yogyakarta.

Qardawi, DR. Yusuf, 1997, Norma dan Etika Ekonomi Islam (terj), Terjemahan, Gema Insani Press, Jakarta.

Sugiyono, Prof. Dr., 2008, Metode Penelitian Kuantitatif, Kualitatif dan $R$ \& $D$, Penerbit Alfabeta, Bandung.

Todaro, Michael P., dan Smith, 2006, Pembangunan Ekonomi, Jilid 1, Edisi Kesembilan, Erlangga, Jakarta.

Permono, Sjechul Hadi, Prof., Dr., K.H., 2005, Formula Zakat Menuju Kesejhteraan Sosial, CV. Aulia, Surabaya. 